\title{
Current state of dental autotransplantation
}

\author{
Daniel Herrera-Gimbernat ${ }^{1}$, Concha Recio-Lora ${ }^{2}$, Daniel Torres-Lagares ${ }^{3}$, Manuel-María Romero-Ruiz ${ }^{2}$, \\ José-Luis Gutiérrez-Pérez ${ }^{4}$
}

${ }^{1}$ Lecturer in Oral Surgery. University of Seville

${ }^{2}$ Professor of the Master in Oral Surgery. University of Seville

${ }^{3}$ Coordinator of the Master in Oral Surgery. University of Seville

${ }^{4}$ Head of Clinical Management Unit (UGC) of Maxillofacial and Oral Surgery. Virgen del Rocío University Hospital. Director of the Master in Oral Surgery. University of Seville

\author{
Correspondence: \\ Facultad de Odontología \\ Universidad de Sevilla \\ C/ Avicena s/n 41009 \\ Sevilla (SPAIN) \\ danieltl@us.es
}

Received: 25/08/2010

Accepted: $14 / 11 / 2010$

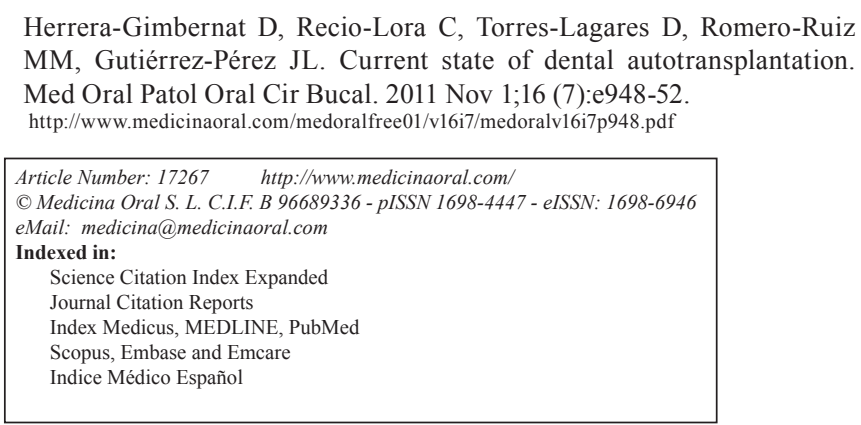

\begin{abstract}
The aim of this study is to analyse the current situation in dental autotransplantations within the different therapeutic alternatives that the dentist has available to replace a tooth in the dental arcade.

For some authors this is an option headed for failure, whereas for others, it is an alternative to keep in mind. In this study we analyse the factors related to the predictability of the technique, based on an analysis of research work published in the scientific literature up to date. We also present two clinical cases performed by our team and their subsequent evaluation.

In spite of the satisfactory results seen when reviewing the existing literature, we cannot say that dental autotransplantation is currently the technique of choice when a tooth is lost, given the predictability of osteointegrated implants.
\end{abstract}

Key words: Dental autotransplantation, dental implant, decision making process.

\section{Introduction}

Dental autotransplantation is defined as the movement of one tooth or dental germ from one position to another, within the same person (1). Tooth reimplantation and transplantation have a long and difficult history, since both procedures have been carried out for centuries, but failed due to healing complications $(1,2)$.

In 1771, John Hunter (precursor in the use of techniques of dental transplantation and reimplantation), showed that a human tooth heterotransplanted within a cock's crest binds to tissue in a similar way as a tooth binds to gums and bony sockets (2).

Since then, several authors have tried to shed light on the subject, but only in the last 30 years, with Professor Andreasen's group (1, 3-5), have the bases been established for a protocol for this treatment.

Currently, with the existence of new technologies and different techniques for rescue surgery (6), dental autotransplantation is an option that is little contemplated; however, it may be useful in concrete situations such as 
substitution of tooth agenesis, ectopic inclusions which cannot be treated by a combination of surgery and orthodontics, or accidental loss or absence of front teeth, especially in young patients $(7,8)$.

\section{Clínical Case: Clinical Application of Au- totransplantation Techniques}

To illustrate this surgical technique we present two clinical cases. The first case is a 28 year-old woman who comes in to consultation due to the persistence of an upper right temporary canine (5.3) and the lack of the permanent replacement of this tooth (1.3).

Using orthopantomography we were able to see the inclusion of the permanent canine in a horizontal position and we determined the palatine position using a Clark X-ray (Figs. 1.A, B).

Due to the difficulties of carrying out rescue surgery by surgical-orthodontic treatment, we considered the possibility of autotransplantation of 1.3 in the bony socket occupied by the deciduous tooth $(9,10)$, which would necessitate subsequent root canal treatment, since this was an adult patient with complete root formation and apical closure (3).

The procedure was carried out following the Andreasen protocol (1, 3-5), which, except for a few small variations, is current today (11). In one operation we extracted 1.3 and 5.3, taking advantage of the space left by the temporary tooth to create a bed to receive the permanent tooth.

A sulcus incision was made from mesial of 1.6 to mesial of 2.4 to obtain a palatine flap with a total thickness that would allow access to the included tooth. Next the deciduous tooth was extracted and a receptor bed was prepared in its bony socket using low-speed burrs with internal irrigation (12), adapted to the size of the canine tooth to be implanted. Once this was completed, we carefully extracted the included tooth trying not to damage the periodontal ligament of the root surface, and reimplanted it in the new bony socket we had created (Fig. 1.D). In this manner, the tooth was outside the mouth for as little time as possible (8).

After placing and adjusting the tooth without any occlusal contact, we replaced the flap and sutured it with cross-stitch suture (12). Next we placed an orthodontic splint made of composite to ensure the stability of the transplant for a 3 week period (13). We prescribed antibiotics, analgesia, and anti-inflammatory drugs and diet and hygiene recommendations during the postoperative period. In the third week, once we had seen that the tooth was stable, we carried out root canal treatment and removed the splint (Fig. 1.C) $(3,8,14)$.

One year later, we can see the excellent state of the grafted tooth with signs of periodontal health and lack of any clinical symptoms (Fig. 1.E). In the periapical

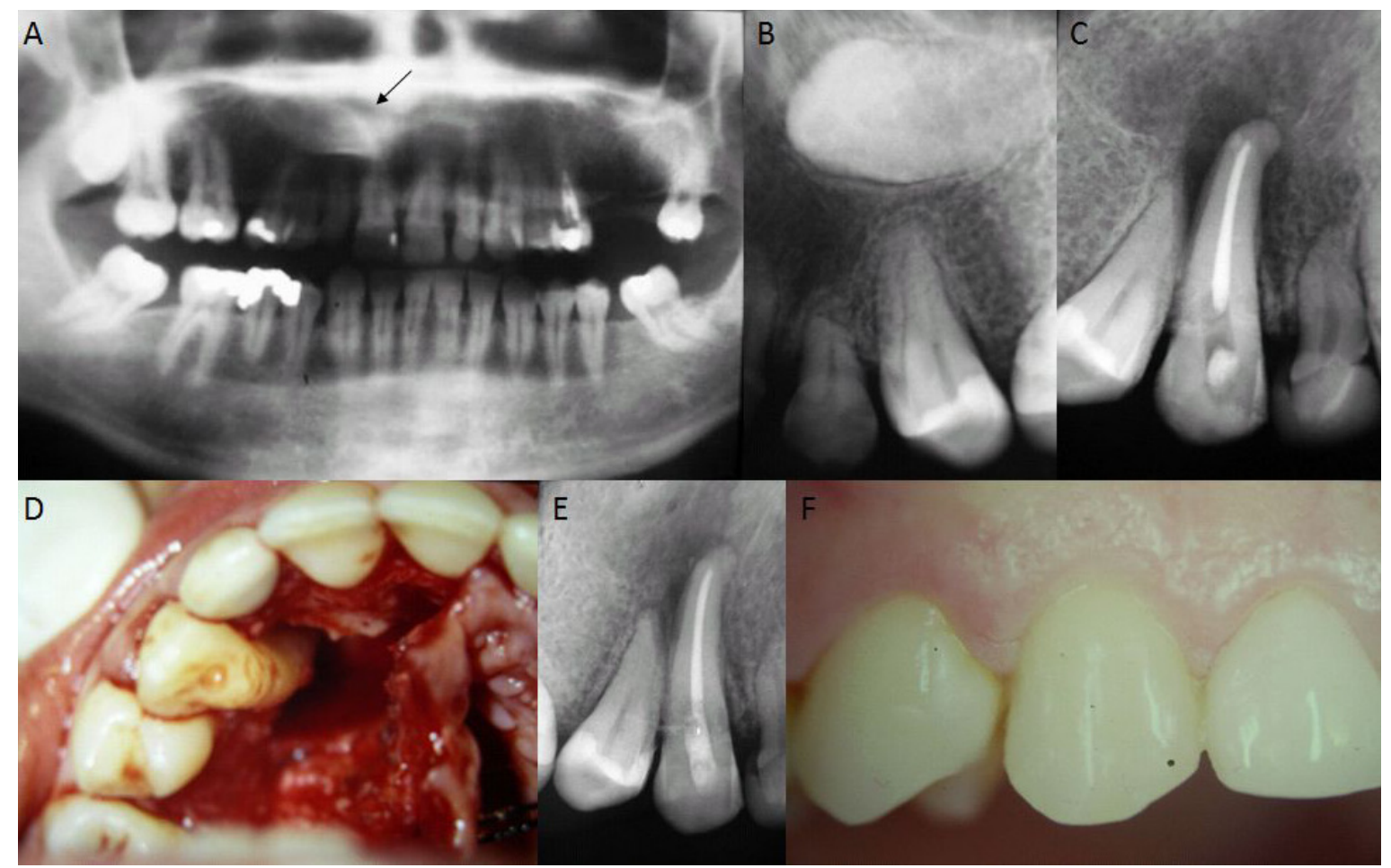

Fig. 1. A) Preoperative Panoramic View: It is possible to see the canine tooth included in the maxilla. B) Periapical preoperative X-ray. C) Root canal treatment after autotransplantation. D) Autotransplantation of a canine to a newly prepared bony socket. E) Interior mouth X-ray one year after surgery. F) Interior mouth image after one year of evolution. 


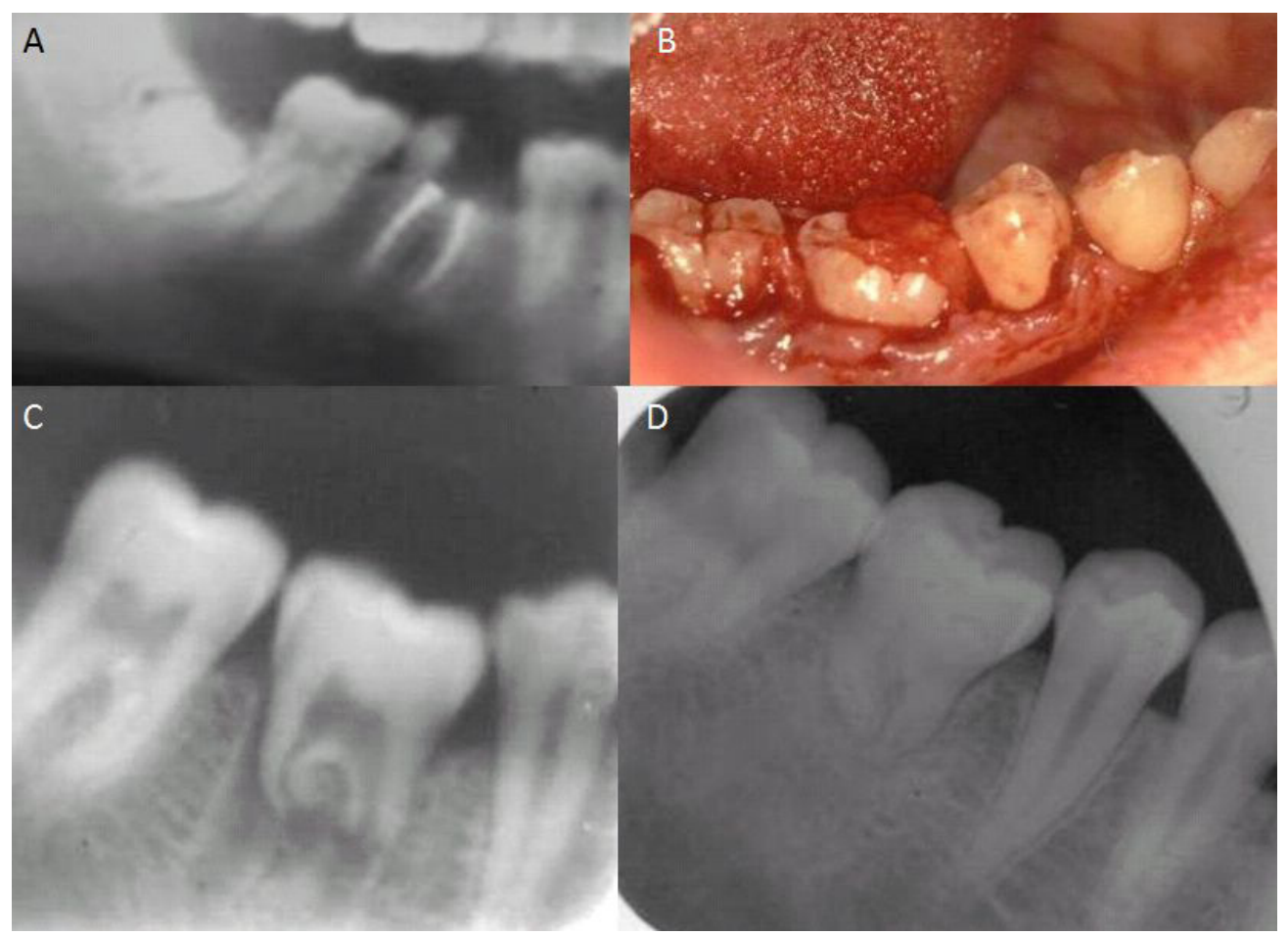

Fig. 2. A) Orthopantomography. B) Clinical image immediately after tooth germ autotransplantation from wisdom-tooth to level 4.6. C) Postoperative X-ray immediately after autotransplantation. D) Postoperative X-ray 2 years after the procedure.

$\mathrm{X}$-ray it is possible to see rizolysis and the formation of bone at the apical level, with a reduction of the initial distal radiolucent area (Fig. 1.F).

The second clinical case was a 19 year-old man who came in to the Dentistry School of the University of Seville referred by his dentist, for assessment of 4.6. During clinical exploration of the mouth we found a state of advanced molar destruction, impossible to preserve (Fig. 2.A).

Our treatment plan consisted of extraction of 4.6 and a possible lower wisdom-tooth germ transplant $(13,15)$ to the bony socket left by 4.6 (Fig. 2.B).

After extraction of the first lower molar, the surgical technique used followed the same steps as in the above case, with the differences involved in the anatomical placement of the included tooth (Fig. 2.C).

After surgery, we carried out clinical follow-up and 6-monthly X-rays. Two years after autotransplantation, it is possible to see, in the control X-ray, how the transplanted tooth has healed normally, and although its root growth has stopped, the tooth is still functional (Fig. 2.D).

\section{Discussion}

In spite of the favourable evolution of these 2 clinical cases presented, we have carried out a review of the literature to determine the validity of the procedure in view of other procedures published. According to our revision, the requirements necessary for the technique to be predictable are:

Age of the patient and degree of root development, these, according to Andreasen (3) and other authors $(2,16,17)$, should be young individuals with incomplete root development to obtain the best results. In adult patients, such as our first case, the transplanted tooth presents apical closure that makes it necessary to perform a root canal treatment to prevent pulpar necrosis. Higher percentages of success are achieved if the donor tooth has a root length between one quarter and one third of its total length $(13,14)$.

The damage caused to periodontal structures during the surgical procedure must be minimal. In this way we can preserve the greatest number of viable cells on the tooth root surface, which will condition periodontal healing and, therefore, the final results $(4,5,10)$.

Most studies published after Andreasen's work (14) follow the same surgical sequence as he did (1), extraction of the tooth from the receptor area and preparation of the receptor bed before extraction of the donor tooth. In this way the time the tooth is outside the bony socket is minimal, which ensures a better evolution.

The receptor bed must be approximately $2 \mathrm{~mm}$ deeper and $1 \mathrm{~mm}$ wider than the donor tooth and it must always be prepared using low-speed internal irrigation burrs to prevent bone overheating. 
One of the most controversial factors is type and time of splinting (13) of the transplanted tooth, although there is coincidence in the fact that the aim is to obtain adequate primary stability during the healing period. Depending on the case, a rigid splint with composite and wire may be used for 4 weeks or a more elastic splint with cross-stitch suture for 1 week. Authors such as Akkocaoglu (18) obtain better results with an elastic splint than with a rigid extensive splint, since they consider this causes a higher number of failures due to ankylosis and pulpar necrosis (7).

After reviewing the subject and finding that tooth autotransplantation is a technique to be considered in select cases, we asked ourselves which was the better option in situations like the ones presented, keeping in mind the predictability of currently used osteointegrated implants.

If we analyse the most recent publications, we find 4 articles (Bauss [13]; Czochrosswka [17], Tsukiboshi [2] and Zachirisson [8]) that clearly defend autotransplantation, based on the following:

-It is a biological procedure in which teeth, especially in the germ phase, have the potential capacity to induce alveolar bone growth.

-It creates a normal periodontal ligament that allows subsequent orthodontic movements and therefore, position adjustment after surgery.

-Eruption is synchronous with neighbouring teeth while there is growth.

-It allows the formation of a normal interdental papilla. -It is a good treatment option with a lower cost.

In spite of these affirmations, it must be kept in mind that there are not more, in total, than 40 articles published over the last 15 years on dental autotransplantation, and that most of them have been written by the same work-group in comparison with the many publications on implants of all types. Therefore, in our opinion, we cannot say there is sufficient data for dental autotransplantation to be considered the treatment of choice when a tooth is lost.

Currently, osteointegrated implants are the therapeutic alternative of choice when replacing a lost tooth, and furthermore they are supported by scientific evidence of more than $95 \%$ (19) survival at 10 years, in comparison with no more than $60 \%$ (11) survival of autotransplanted teeth. The great advantage of implants in comparison with dental transplants is their predictability, which inclines the cost/benefit equation in their favour.

Therefore, we can conclude that:

1.- Dental autotransplantation is a possible therapeutic option if carried out appropriately and in carefully selected cases. Patients must be informed of all the risks.

2.- The greatest limitation of autotransplantation but at the same time its major indication is that it must be performed in young patients who have not completed their root development, for the procedure to be predictable.
In children, especially in the case of loss of front teeth, this procedure may be best, since it has an important role in the preservation of alveolar bone if it should be necessary to use implants in the future.

3.- It is a surgical procedure that requires professional skill and patient and parent collaboration and understanding.

4.- In spite of the results of the studies analysed and the cases presented here, we believe that autotransplantation is currently not the technique of choice for a lost tooth, since the complications associated with the technique mean it is not predictable.

\section{References}

References with links to Crossref - DOI

1. Andreasen JO, Paulsen HU, Yu Z, Ahlquist R, Bayer T, Schwartz O. A long-term study of 370 autotransplanted premolars. Part I. Surgical procedures and standardized techniques for monitoring healing. Eur J Orthod. 1990;12:3-13.

2. Tsukiboshi M. Autotransplantation of teeth: requirements for predictable success. Dent Traumatol. 2002;18:157-80.

3. Andreasen JO, Paulsen HU, Yu Z, Bayer T, Schwartz O. A longterm study of 370 autotransplanted premolars. Part II. Tooth survival and pulp healing subsequent to transplantation. Eur J Orthod. 1990;12:14-24.

4. Andreasen JO, Paulsen HU, Yu Z, Schwartz O. A long-term study of 370 autotransplanted premolars. Part III. Periodontal healing subsequent to transplantation. Eur J Orthod. 1990;12:25-37.

5. Andreasen JO, Paulsen HU, Yu Z, Bayer T. A long-term study of 370 autotransplanted premolars. Part IV. Root development subsequent to transplantation. Eur J Orthod. 1990;12:38-50.

6. García-Calderón M, Torres-Lagares D, González-Martín M, Gutiérrez-Pérez JL. Rescue surgery (surgical repositioning) of impacted lower second molars. Med Oral Patol Oral Cir Bucal. 2005;10:44853.

7. Czochrowska EM, Stenvik A, Album B, Zachrisson BU. Autotransplantation of premolars to replace maxillary incisors: a comparison with natural incisors. Am J Orthod Dentofacial Orthop. 2000;118:592-600.

8. Zachrisson BU, Stenvik A, Haanaes HR. Management of missing maxillary anterior teeth with emphasis on autotransplantation. Am J Orthod Dentofacial Orthop. $2004 ; 126: 284-8$.

9. Czochrowska EM, Stenvik A, Bjercke B, Zachrisson BU. Outcome of tooth transplantation: survival and success rates 17-41 years posttreatment. Am J Orthod Dentofacial Orthop. 2002;121:110-9.

10. Teixeira CS, Pasternak B Jr, Vansan LP, Sousa-Neto MD. Autogenous transplantation of teeth with complete root formation: two case reports. Int Endod J. 2006;39:977-85.

11. Kallu R, Vinckier F, Politis C, Mwalili S, Willems G. Tooth transplantations: a descriptive retrospective study. Int J Oral Maxillofac Surg. 2005;34:745-55.

12. Clokie CM, Yau DM, Chano L. Autogenous tooth transplantation: an alternative to dental implant placement? J Can Dent Assoc. 2001;67:92-6.

13. Bauss O, Schilke R, Fenske C, Engelke W, Kiliaridis S. Autotransplantation of immature third molars: influence of different splinting methods and fixation periods. Dent Traumatol. 2002;18:322-8.

14. Díaz JA, Almeida AM, Benavente AA. Tooth transplantation after dental injury sequelae in children. Dent Traumatol. 2008;24:320-7.

15. Bauss O, Zonios I, Rahman A. Root development of immature third molars transplanted to surgically created sockets. J Oral Maxillofac Surg. 2008;66:1200-11.

16. Paulsen HU, Andreasen JO. Eruption of premolars subsequent to autotransplantation. A longitudinal radiographic study. Eur J Orthod. 1998;20:45-55.

17. Czochrowska EM, Stenvik A, Zachrisson BU. The esthetic out- 
come of autotransplanted premolars replacing maxillary incisors. Dent Traumatol. 2002;18:237-45.

18. Akkocaoglu M, Kasaboglu O. Success rate of autotransplanted teeth without stabilisation by splints: a long-term clinical and radiological follow-up. Br J Oral Maxillofac Surg. 2005;43:31-5.

19. Eckert SE, Choi YG, Sánchez AR, Koka S. Comparison of dental implant systems: quality of clinical evidence and prediction of 5-year survival. Int J Oral Maxillofac Implants. 2005;20:406-15. 